\title{
Pursuit of Harmony: Relational and Individual Predictors of Sexual Passion Expression
}

\author{
Nathan D. Leonhardt \\ University of Toronto \\ Dean M. Busby \\ Brigham Young University - Provo, dean_busby@byu.edu \\ Chanae Valdez \\ University of San Diego
}

Follow this and additional works at: https://scholarsarchive.byu.edu/facpub

Part of the Other Social and Behavioral Sciences Commons

\section{Original Publication Citation}

Leonhardt, N. D., Busby, D. M., Valdez, C. (2020). Pursuit of Harmony: Relational and individual predictors of sexual passion expression. Archives of Sexual Behavior.

\section{BYU ScholarsArchive Citation}

Leonhardt, Nathan D.; Busby, Dean M.; and Valdez, Chanae, "Pursuit of Harmony: Relational and Individual Predictors of Sexual Passion Expression" (2020). Faculty Publications. 4647.

https://scholarsarchive.byu.edu/facpub/4647

This Peer-Reviewed Article is brought to you for free and open access by BYU ScholarsArchive. It has been accepted for inclusion in Faculty Publications by an authorized administrator of BYU ScholarsArchive. For more information, please contact ellen_amatangelo@byu.edu. 


\title{
Pursuit of Harmony: Relational and Individual Predictors of Sexual Passion Expression
}

\author{
Nathan D. Leonhardt ${ }^{1}$ (D) Dean M. Busby ${ }^{2} \cdot$ Chanae Valdez $^{3}$
}

Received: 7 July 2018 / Revised: 24 March 2020 / Accepted: 9 June 2020 / Published online: 5 July 2020

๑) Springer Science+Business Media, LLC, part of Springer Nature 2020

\begin{abstract}
Harmonious, obsessive, and inhibited sexual passion comprise the Triadic Model of Sexual Passion. Research has shown that together they play an important role in sexual and relationship satisfaction. Little is known, however, about the factors that predict the likelihood of having these types of passion expression. Using a Mechanical Turk sample of 1414 individuals, we estimated structural equation models to evaluate how relationship factors (i.e., relationship length, sexual desire, sexual drive) and individual factors (i.e., attachment style, childhood abuse, personality) predict the three constructs from the Triadic Model of Sexual Passion. In general, those with higher sexual desire, secure attachment, no childhood abuse, and low impulsivity and shyness were most likely to report optimal sexual passion (higher harmonious, lower inhibited, and lower obsessive sexual passion). By better understanding how these factors predict sexual passion expression, couples may have an increased likelihood of experiencing harmonious sexual passion in their sexual relationships.
\end{abstract}

Keywords Sexual desire $\cdot$ Attachment $\cdot$ Sexual abuse $\cdot$ Triadic model of sexual passion

\section{Introduction}

Some people wake up in the morning smiling because today is the day they get to play basketball. Some musicians practice their instruments for hours a day that feel like minutes. Some scientists tirelessly dedicate their lives to understanding a new phenomenon. All these examples highlight the experience of passion in life. This passion brings a sense of excitement that many regard as being a piece of the puzzle to what makes life worth living (Vallerand, 2015). But the way passion is approached can differentiate outcomes. On the one hand, someone could have a harmonious approach to their passion. This is where they maintain control of passion and keep it in balance with other life priorities. For example, a scientist may be excited about a current project, but sets clear boundaries about finishing work in time each day to eat dinner with family.

Nathan D. Leonhardt

nathan.leonhardt@mail.utoronto.ca

1 Department of Psychology, University of Toronto, 3359 Mississauga Road, Mississauga, ON L5L 1C6, Canada

2 School of Family Life, Brigham Young University, Provo, UT, USA

3 Marital and Family Therapy, University of San Diego, San Diego, CA, USA
On the other hand, a non-harmonious passion may be poorly integrated into the scientist's life. For example, a scientist may love working, but feels an almost involuntary pull to work; the passion consumes their life and the scientist no longer makes time for family, friends, or any other activities they once found enjoyable.

A growing body of research has highlighted the value of harmonious passion in a variety of domains. It has been shown to be beneficial for work performance (Ho, Wong, \& Lee, 2011), sports performance (Vallerand, Rousseau, Grouzet, Dumais, \& Grenier, 2006), romantic relationships (Acevedo \& Aron, 2009; Ratelle, Carbonneau, Vallerand, \& Mageau, 2013), and even seems to be helpful for finding meaning in life (Vallerand, 2015; Vallerand \& Verner-Filion, 2013). Little, however, is understood about sexual passion (e.g., Philippe, Vallerand, BernardDesrosiers, Guilbault, \& Rajotte, 2017; Philippe et al., 2019), particularly how it is expressed in committed relationships (Busby, Chiu, Leonhardt, \& Iliff, 2019a; Busby, Leonhardt, \& James, 2019b). Researchers recently asserted the Triadic Model of Sexual Passion, comprising three dimensions of sexual passion expression in a committed relationship: harmonious sexual passion (an autonomous, balanced, controlled passion) and two non-harmonious, maladaptive forms of sexual passion: (a) an obsessive, undercontrolled sexual passion, and (b) an inhibited, overcontrolled sexual passion. 
As evidence is beginning to suggest the value of sexual passion expression (Philippe et al., 2017, 2019), particularly in committed relationship (Busby et al., 2019a, b), understanding the antecedents of passion is an important endeavor for both applied and basic researchers, for lay and professional audiences. We propose the approach to sexual passion is contingent upon a variety of relationship factors (i.e., relationship length, sexual desire toward the partner, sexual drive) and individual factors (i.e., attachment security, childhood abuse, personality). First, we give a brief overview of how passion research builds up to a current understanding of the Triadic Model of Sexual Passion. Second, we hypothesize how our identified relational and individual factors may predict the expression of harmonious, obsessive, and inhibited sexual passion in a committed relationship.

\section{The Triadic Model of Sexual Passion}

Theoretical and empirical advancements have engendered the move from a unidimensional (Hatfield \& Rapson, 1990; Sternberg, 1986), to a dualistic (Philippe et al., 2017; Vallerand et al., 2003), and finally to a Triadic Model of Sexual Passion (Busby et al., 2019a, b). In a well-researched field, Sternberg (1986, 1988) and Hatfield (e.g., Hatfield \& Rapson, 1990, 1993; Kim \& Hatfield, 2004) have conceptualized passion as an obsessive, emotionally driven, longing for a partner. This ongoing line of work conceptualizing passion in this manner has value. It informs our study, but the way we evaluate passion has important distinctions. First, previous work has focused on romantic passion; limited work has specified passion as "sexual." Furthermore, in past studies, passion is typically conceptualized as an obsession that controls the individual (for an exception with a more detailed breakdown, see Acevedo \& Aron, 2009). The manic and obsessive element of this passion inform our current understanding of obsessive sexual passion expression, as it includes an undercontrolled, unbalanced preoccupation with sexuality. This may lead the individual to feeling so interested in sexual activity with the partner that there is little interest in any other activities. It may lead to acting on the intense urge to engage in sexual activity, not worrying about whether the passion is in harmony with other aspects of life.

Philippe et al. $(2017,2019)$ critiqued the focus on a unidimensional (e.g., Hatfield \& Rapson, 1990, 1993; Kim \& Hatfield, 2004; Sternberg, 1986, 1988), manic, obsessive passion. They criticized the focus on passion primarily controlling the individual and suggested the value of research on how to control the sexual passion. Philippe et al. (2017) suggested that in addition to an obsessive element of sexual passion expression, a more harmonious sexual passion expression exists. This harmonious sexual passion implies balanced, autonomous, controlled engagement in sexual activity; this has been shown to lead to positive individual and relational outcomes (Philippe et al., 2017).

Most recently, Busby et al. (2019a, b) agreed with the conceptualizations of obsessive and harmonious sexual passions (Philippe et al., 2017). Busby et al. (2019a) also suggested that sexual passion in a committed relationship can take the form of inhibited sexual passion. As previously mentioned, inhibited sexual passion, similar to obsessive sexual passion, comes with an unhealthy, unbalanced preoccupation with sexuality. Inhibited sexual passion, however, comes from an overcontrol of sexuality rather than an undercontrol. The individual is so preoccupied (likely from worry) with controlling their sexuality that they are unable to freely, autonomously engage in sexual experiences. Creating a construct for inhibited sexual passion was justified because several nuances distinguish passion in a committed sexual relationship from passions in other areas of life: (1) the appetitive nature of sexuality, reflecting an almost universal desire among individuals to participate in sexual activity (e.g., Bogaert, 2004; Kinsey, Pomeroy, \& Martin, 1948), (2) the heavy level of moral and social constraints societies might place on sexuality (e.g., Augustine, 1990), and (3) the almost universal expectation that sexual activity will be a regular occurrence in committed relationships (e.g., Elliott \& Umberson, 2008).

Inhibited sexual passion is likely made possible by the combination of feeling moral or social constraint in expressing sexual passion while simultaneously being expected to participate in appetitive sexual activity. Inhibited sexual passion is not to be confused with a lack of interest in sexual activity or a lack of passion (Busby et al., 2019a, b; Philippe et al., 2017). Similar to how a shy individual may desire to socially engage with peers, but feels inhibited during social situations (Coplan, Prakash, O’Neil, \& Armer, 2004), someone with inhibited sexual passion can desire to participate in sexual activity, yet feel reluctant acting upon an almost universal sexual appetite.

Validation of the Triadic Model of Sexual Passion (i.e., harmonious, obsessive, and inhibited) remains in its youth. Measurement of the three constructs was established in a large cross-sectional study. Measures for harmonious, obsessive, and inhibited sexual passion expression were shown to be psychometrically sound through reliability analyses and confirmatory factor analyses. Harmonious sexual passion expression was positively correlated with obsessive sexual passion expression and negatively correlated with inhibited sexual passion expression. Interestingly, obsessive and inhibited sexual passion expression were positively correlated, perhaps suggesting an underlying dysregulation surrounding how to express sexual passion. The constructs also showed clear distinction from both sexual desire for a partner and sexual drive. Sexual desire for a partner and sexual drive focus more on the extent someone wants to engage in sexual activity; sexual passion expression focuses more on the manner that sexual interest is controlled or integrated into one's life. Together the passion expression 
constructs provide strong prediction for sexual satisfaction and overall relationship satisfaction (Busby et al., 2019a), with harmonious sexual passion expression being strongly, positively associated with both, inhibited sexual passion expression being negatively associated with both, and obsessive sexual passion expression having an inconsistent negative association with sexual satisfaction.

Another study (Busby et al., 2019b) recently added evidence for the three constructs psychometric utility and predictive validity through cross-sectional samples of 1776 individuals, 244 couples, and a nationally representative sample of 1813 couples. The three constructs for passion expression in a committed relationship were distinguished from a general approach to passion in life, romantic passion, and general sexual passion through confirmatory factor analyses. The three constructs also met the passion criteria established in previous studies (e.g., Philippe et al., 2017; Vallerand et al., 2003).

\section{Predictors of Sexual Passion}

A next logical step in validating the constructs is to assess their antecedents, including both relationship (i.e., relationship length, sexual desire toward a partner, sexual drive) and individual factors (i.e., attachment security, childhood abuse, personality). By assessing additional correlates of the psychometrically sound constructs from the Triadic Model of Sexual Passion, we can gain clearer perspective on the value for this line of research. With moderate correlations between theoretically linked factors, we can begin to be more confident in construct validity.

\section{Relationship Factors}

Several relationship factors are likely important in predicting sexual passion expression, including relationship length, sexual desire toward a partner, and sexual drive. Relationship length is important to consider as a predictor of sexual passion expression in a committed relationship, as debates exist about whether passionate love can be maintained in a committed relationship (Aron \& Aron, 1986; Sternberg, 1986). Recently, a study has disentangled the obsession/manic element from a more harmonious element of romantic love. Acevedo and Aron (2009) found that while relationship length was connected to lower obsession, long-term couples were still able to retain vibrant, romantic relationships filled with passion and sexual interest. Our construct of obsessive sexual passion resembles the obsessive element of the study's romantic love, while our construct of harmonious sexual passion more closely resembles the study's non-obsessive romantic love. For that reason, we hypothesized (H1a) that relationship length would be negatively associated with obsessive sexual passion while simultaneously hypothesizing that relationship length would not be associated with harmonious sexual passion.
Sexual desire is also important to consider as a relationship factor. Sexual desire has had many conceptualizations, some focusing specifically on the sexual desire felt toward a specific partner, while others have focused more on a general, biologically driven sexual desire (Brotto \& Smith, 2014; Levine, 1987). Although these two factors overlap, when evaluated simultaneously they likely produce different outcomes (Brotto \& Smith, 2014, Levine, 1987), especially when the outcome of interest is sexual passion directed toward a committed partner. In fact, when sexual desire and sexual drive are evaluated simultaneously in a model, the leftover variance for sexual drive might even tap into sexual interest outside of the committed sexual relationship.

Those with higher sexual desire toward a partner and sexual drive may have higher obsessive sexual passion, as high sexual desire is associated with potentially losing control of sexuality (Wetterneck, Burgess, Short, Smith, \& Cervantes, 2012). However, sexual desire toward a partner and sexual drive are likely to differ in their associations for harmonious sexual passion. Sexual desire specifically directed at a romantic partner seems more likely linked to a positive, balanced, and integrated development of sexual passion in a committed relationship. Meanwhile, a more general sexual drive, not directed specifically as desire toward the partner, may produce a more maladaptive passion. A strong sexual drive (independent of the sexual desire toward the committed partner) could reflect an obsession with sexuality in general that is incongruent with harmonious sexual passion. Inhibited sexual passion and different types of sexual desire can trend separately, as those with moderate sexual desire or drive may still have high inhibited sexual passion. However, this may or may not be the case with the average participant, as past research has suggested that a strong desire to engage in sexual activity has been connected with a likelihood of overcoming sexual inhibitions (Birnbaum, Mikulincer, Szepsenwol, Shaver, $\&$ Mizrahi, 2014).

With these considerations, we hypothesized (H1b) that sexual desire toward the partner will be positively associated with harmonious and obsessive sexual passion, and negatively associated with inhibited sexual passion. Alternatively, we hypothesized (H1c) that sexual drive, outside of desire for the partner, will be associated with lower harmonious sexual passion, higher obsessive sexual passion, and lower inhibited sexual passion.

\section{Attachment Security}

Attachment security has been connected to relational outcomes that may be part of the development of sexual passion. For example, considering that anxiously attached individuals report lower autonomy (Van Petegem, Beyers, Brenning, \& Vansteenkiste, 2013), and autonomy is a crucial element for harmonious integration of passion, those more anxiously attached may have greater difficulty developing harmonious 
sexual passion (Vallerand, 2015). Furthermore, those with anxious attachment ambivalently press for closeness (an element of obsession), but also may be afraid of getting too close in a relationship (an element of inhibition; see Mikulincer $\&$ Shaver, 2016). This suggests the possibility that those who are anxiously attached may rotate between maladaptive strategies in coping with an unhealthy development of passion. For those reasons, we hypothesized (H2a) that those with anxious attachment will report higher obsessive and inhibited sexual passion, and lower harmonious sexual passion.

Alternatively, avoidant attachment has been linked to lower novelty seeking (Carnelley \& Ruscher, 2000), exploratory interest (Wu \& Yang, 2012), and focus on self-growth (Mikulincer \& Shaver, 2016). Considering self-growth being negatively connected with avoidant attachment and positively connected with harmonious sexual passion (Carbonneau, Vallerand, Lavigne, \& Paquet, 2016), those with avoidant attachment may be less likely to develop harmonious sexual passion. Unlike the anxiously attached who display ambivalence in their relationships, those who are avoidant may only approach their maladaptive sexual passion through inhibition, as avoidance is connected to traits commonly associated with inhibited passion, such as a fear of intimacy (Doi \& Thelan, 1993), and inhibited self-disclosure (Collins, Cooper, Albino, $\&$ Allard, 2002). For these reasons, we hypothesized (H2b) that higher avoidance will be associated with lower harmonious sexual passion and higher inhibited sexual passion.

\section{Childhood Abuse}

With early, traumatic childhood experiences, people often grow to be less trusting, less secure, and generally more troubled adults (Mikulincer, Shaver, \& Solomon, 2015). Previous research has suggested that child abuse is related to maladaptive approaches to sexuality that lead to higher difficulties in a sexual relationship, by means of both higher inhibition and hyperactivation of the sexual behavioral system (Seehuus, Clifton, \& Rellini, 2015; Vaillancourt-Morel et al., 2015). Therefore, they may be less likely to develop an autonomous, harmonious passion (Vallerand, 2015).

We expect sexual abuse in particular to result in maladaptive development of sexual passion, as the coercion to participate in sexual activity directly intrudes upon the likelihood of autonomously developing harmonious passion in the sexual domain. This maladaptation is also likely to be manifest in increased obsessive and inhibited sexual passion, as previous research has suggested that sexual abuse is linked to both an increased avoidance and compulsivity surrounding sexuality (Vaillancourt-Morel et al., 2015). This avoidant sexuality has conceptual overlap with our inhibited sexual passion construct, whereas compulsivity has conceptual overlap (but still distinction; Philippe et al., 2017) with our obsessive sexual passion construct. It seems possible that victims of sexual abuse may rotate between maladaptive strategies (obsessive and inhibited) in coping with sexual passion in their attempts to make sense of their past trauma.

We hypothesized (H3a) both physical abuse and sexual abuse to be negatively correlated with harmonious sexual passion and positively correlated with both obsessive and inhibited passion. We also hypothesized (H3b) that when physical and sexual abuse are evaluated together, sexual abuse will be more important than physical abuse in predicting each construct of sexual passion because it addresses the specific domain of sexuality (Seehuus et al., 2015).

\section{Personality}

Research has shown that both impulsivity and shyness have resulted in maladaptive relationship outcomes (Asendorpf, Denissen, \& van Aken, 2008; Luster, Nelson, Poulsen, \& Willoughby, 2013; Nelson et al., 2008). These maladaptive relationship outcomes likely come partially from suboptimal internal regulation (Eisenberg et al., 2007; Rubin \& Asendorpf, 1993), which limits an individual's ability to develop harmonious passion and likely increases the chances of developing a maladaptive passion (Vallerand, 2015). Impulsivity (Eisenberg et al., 2007) may be one specific aspect of personality that taps into the idea of limited autonomy and undercontrolled personality, restricting the harmonious development of passion and developing a more obsessive passion. Meanwhile, shyness (Rubin \& Asendorpf, 1993) may tap into the idea of limited autonomy and overcontrolled personality, restricting the harmonious development of passion and developing a more inhibited passion. Especially when all these variables are evaluated simultaneously, it seems unlikely that impulsivity would be related to inhibited sexual passion or that shyness would be linked to obsessive sexual passion because impulsivity is unlikely to directly explain variance for overcontrol (Eisenberg et al., 2007) and shyness is unlikely to directly explain variance for undercontrol (Rubin \& Asendorpf, 1993). For these reasons, we hypothesized (H4a) that impulsivity would be associated with lower harmonious sexual passion and higher obsessive sexual passion, yet unrelated to inhibited sexual passion. We also hypothesized (H4b) that shyness would be associated with lower harmonious sexual passion and higher inhibited sexual passion, yet unrelated to obsessive sexual passion.

\section{Current Study}

The purpose of this study was to explore relational and individual predictors of sexual passion. We first established bivariate correlations between the predictors of sexual passion in a committed relationship (relationship factors and individual factors), and assessed their associations with the three identified aspects of sexual passion (harmonious, obsessive, and inhibited). After assessing the bivariate associations, we also simultaneously 
assessed the associations between our predictors and sexual passion through structural equation modeling. By assessing several important predictors, we hoped to increase the empirical evidence showing the uniqueness of sexual passion as a construct, and specifically add support to the Triadic Model of Sexual Passion by showing how harmonious, obsessive, and inhibited sexual passion differentiate. Because of the exploratory nature of this study and because of differences between women and men in the connection between many sexuality outcomes (Katz-Wise \& Hyde, 2014), we also decided to explore patterns by gender. As this study was exploratory, we did not have specific predictions for if/how men and women might differ. We went into the analyses ready to assess differences between genders as needed based upon preliminary analyses (MANOVA, bivariate correlations, and measurement invariance tests).

\section{Method}

\section{Participants and Procedure}

The final analytical sample of the present study consisted of 1414 individuals in a committed romantic relationship (771 women, 643 men), sampled from the Amazon Mechanical Turk (MTurk) Web site (http://www.mturk.com). MTurk is a Web site dedicated to online labor and is used to employ "workers" from around the world to complete specific tasks. Regarding the current project, a job was posted inviting participants to complete a short 10-15-min survey on sexuality and passion in a relationship. Participants were instructed that they needed to be English speaking, and those who were interested were directed to a separate Web site to complete an online assessment. Before beginning the online survey, participants were asked to indicate informed consent and were informed about their rights as a research participant. Upon completion of the survey, participants were thanked for their time and given compensation of $\$ 0.50$, a rate similar to comparable tasks on the MTurk Web site. Scholars have noted that samples from MTurk are very similar to other diverse behavioral research samples, and several scholars have replicated previous research results on MTurk to provide evidence for the validity of the sample (Paolacci, Chandler, \& Ipeirotis, 2010; Suri \& Watts, 2011). At the same time, some concerns have arisen about the quality of data from MTurk studies (Peer, Vosgerau, \& Acquisti, 2014). The sample originally had 1629 individuals, but to ensure quality data participants were removed who missed one of the attention check questions (e.g., If you are reading this closely, please select "strongly agree"). We also ensured that there were no bots or duplicate data by checking for patterns in IP addresses and GPS coordinates (Bai, 2018). Furthermore, the data were collected in 2016, before major concerns about bots.
The participants ranged in age from 18 to 83 with the mean age of the sample being 34.15 years $(\mathrm{SD}=10.49)$. All the participants reported being a US citizen. Seventy-six percent of the sample was white, $7.4 \%$ were black, $5.4 \%$ were Asian, and $4.9 \%$ were Latino. Participants also reported a variety of religious affiliations: $27.0 \%$ reported Protestant, $19.4 \%$ reported Catholic, $2.3 \%$ reported Hindu, $2.0 \%$ reported Jewish, $1.7 \%$ reported Buddhist, and $32.5 \%$ reported no religious affiliation. Eleven percent reported an "other" religious affiliation.

For relationship status, $43.9 \%$ of participants reported "Exclusively dating someone," $7.3 \%$ reported being "Engaged," and $48.7 \%$ reported being "Married." The length that participants had been in a relationship ranged from 1 month to 603 months with the mean length of relationship being 82.14 months ( $\mathrm{SD}=91.146)$. For education and income, $28.6 \%$ of the sample reported completing a high school education or less, and the remaining $71.4 \%$ reported receiving some kind of degree, with $12.4 \%$ of the sample receiving an advanced degree. The majority of the sample reported an income between $\$ 20,000$ and $\$ 100,000(67.4 \%)$, while $24.3 \%$ reported an income under $\$ 20,000$, and $7.7 \%$ reported an income above $\$ 100,000$.

\section{Measures}

Observed variables were used for all preliminary analyses (MANOVA by gender and correlations). In the final SEM models, latent variables were used for outcomes of interest (sexual passion variables), as well as the abuse scales. ${ }^{1}$

\section{Sexual Passion}

Sexual passion was assessed as three distinct constructs developed by (Busby et al., 2019a) on 5-point Likert scales $(1=$ never $; 5=$ very often $)$ : harmonious sexual passion, obsessive sexual passion, and inhibited sexual passion. To be clear, the scales do not capture the degree of total passion; they capture the manner in which someone expresses their sexual passion toward their partner. Five items were used to form a latent variable for harmonious sexual passion (e.g., "Excitement about sexual activities with my partner is balanced with the rest of my life"). The lowest factor loading for harmonious sexual passion was .54 for women and .45 for men in the final

\footnotetext{
$\overline{1}$ We attempted to use latent variables for both attachment constructs and personality constructs. But the items did not load ideally onto the constructs of interest, resulting in less optimal model fit. In fact, the latent variables for avoidance and anxious attachment seemingly lost their distinction, with their conflation leading to a problematic model. Results available at https://osf.io/5zveq/. For these reasons, we decided to simply insert the scales as observed variables, as these scales for attachment (Simpson, Rholes, \& Phillips, 1996), impulsivity (Tangney, Baumeister, \& Boone, 2004), and shyness (Coplan et al., 2004), have shown validation in past research.
} 
structural equation model, and the reliability was acceptable for women $(\alpha=.86)$ and men $(\alpha=.84)$. Six items were used to form a latent variable for obsessive sexual passion (e.g., "I can easily get obsessed about sexual activities with my partner"). The lowest factor loading for obsessive sexual passion was .58 for women and .55 for men in the final structural equation model, and the reliability was acceptable for women $(\alpha=.87)$ and men $(\alpha=.85)$. Finally, five items were used to form a latent variable for inhibited sexual passion (e.g., "I often feel reluctant to act on sexual urges that I have for my partner"). The lowest factor loading for inhibited sexual passion was .61 for women and .59 for men in the final structural equation model, and the reliability was acceptable for women $(\alpha=.78)$ and men $(\alpha=.78)$.

\section{Relationship Factors}

Relationship factors were each evaluated with one item. Relationship length was assessed with the open-ended question "How many months have you been in a relationship with your partner?" Sexual desire was assessed with one item on a 7-point Likert scale "How often do you desire to have sexual intercourse with your partner?" $(1=$ never $;=$ more than once $a$ day). Sexual drive was also assessed with one item, but on a 6-point Likert scale: "During the past 30 days, on how many days have you felt sexual drive? Sexual drive is defined as wanting to have sexual experience, thinking about having sex, or feeling frustrated due to lack of sex." $(1=$ no days; $6=$ several times a day $)$.

\section{Attachment Security}

Attachment security was assessed using the Adult Attachment Questionnaire (AAQ; Griffin \& Bartholomew, 1994; Simpson, Rholes, \& Nelligan, 1992; Simpson et al., 1996), which is on a 7-point Likert scale ( $1=$ strongly disagree $; 7=$ strongly agree $)$. Attachment anxiety was formed by taking the average of the 9 items (e.g., "Others often are reluctant to get as close as I would like"). Attachment avoidance was formed by taking the average of the 8 items (e.g., "I'm not very comfortable having to depend on other people"). In initial validation research, anxious attachment had an internal consistency of .76 for women and .72 for men and avoidant attachment had an internal consistency of .74 for women and .70 for men. Factor analyses showed that the two constructs were distinct from one another. Furthermore, these scales were correlated as expected with observer ratings (Simpson et al., 1996). In this sample, attachment anxiety Cronbach's alpha was .83 for women and .79 for men. Attachment avoidance Cronbach's alpha was .86 for women and .82 for men.

\section{Childhood Abuse}

Child abuse was assessed with items taken from the Childhood Trauma Questionnaire (Bernstein et al., 1994). In the initial validation study, the physical and sexual abuse subscales were two of four subscales revealed through factors analyses. The physical abuse scale had a Cronbach alpha of .94 and a test-retest reliability of .82. The sexual abuse subscale had a Cronbach alpha of .92 and a test-retest reliability of .81 . The subscales also showed convergence based on a childhood trauma interview.

In this study, both scales were originally assessed on a 5-point Likert scale $(1=$ never true; $5=$ very often true $)$. However, for sexual abuse, the sample heavily favored the scale point "never true" resulting in a violation of the assumption for normal distribution. To counter the violation of normal distribution, four dichotomous indicators assessing any agreement with the items were used to form the manifest variable for preliminary analyses and the latent variable for the SEM models. Physical abuse was assessed with three items (e.g., "In my family growing up, people hit me so hard that it left me with bruises or marks"). The Cronbach's alpha was .90 for women and .85 for men. In the final structural equation model (explained in "Results" section), the lowest factor loading for physical abuse was .73 for women and .65 for men. Sexual abuse was assessed with four items (e.g., "In my family growing up, someone tried to touch me in a sexual way or tried to make me touch them") and Cronbach's alpha was .95 for women and .96 for men. The lowest factor loading for sexual abuse was .77 for women and .87 for men and in the final structural equation model.

\section{Personality}

Personality factors included impulsivity and shyness. Impulsivity was assessed by averaging the responses of seven items from the self-control scale (Tangney et al., 2004). The scale was on a 4 -point Likert scale $(1=$ never true $; 4=$ always true) with an example item being "I often act without thinking through all the alternatives." In the initial validation study, the scale showed an acceptable Cronbach alpha of .83 and .85 in Studies 1 and 2, respectively. The study also showed a .87 test-retest reliability. For predictive validity, lower impulsivity predicted less binge eating and alcohol abuse, better relationships and interpersonal skills, secure attachment, and more optimal emotional responses. In this study, Cronbach's alpha was .80 for women and .78 for men.

Shyness was assessed on a 5-point Likert scale ( $1=$ strongly disagree; $5=$ strongly agree) with five items from the Child Social Preference scale (Coplan et al., 2004) that had been adapted for adults (e.g., "I'd like to hang out with other people, but I'm sometimes nervous to"). In the initial validation study, shyness had Cronbach's alphas of .87 and .89 in two samples. The questions showed predictive validity with maternal ratings of child temperament, social goals, teacher ratings of child social adjustment, observations of child free-play behaviors, and a child interview assessing perceived competence and 
Table 1 Differences between men and women for variables of interest

\begin{tabular}{|c|c|c|c|c|c|c|}
\hline \multirow[t]{2}{*}{ Variable } & \multicolumn{2}{|l|}{ Men } & \multicolumn{2}{|c|}{ Women } & \multirow[t]{2}{*}{ Response range } & \multirow[t]{2}{*}{$F$ value } \\
\hline & M & SD & M & SD & & \\
\hline Relationship length (months) & 82.24 & 94.63 & 82.85 & 89.06 & $1-603$ & .015 \\
\hline Sexual desire & 4.90 & 1.26 & 4.68 & 1.23 & $1-7$ & $11.28 * *$ \\
\hline Sexual drive & 4.21 & 1.25 & 3.55 & 1.12 & $1-6$ & $102.55 * * *$ \\
\hline Attachment anxiety & 3.23 & 1.01 & 3.35 & 1.17 & $1-7$ & 1.10 \\
\hline Attachment avoidance & 3.73 & 1.07 & 3.89 & 1.20 & $1-7$ & $2.55^{*}$ \\
\hline Physical abuse & 1.91 & 1.05 & 1.92 & 1.16 & $1-5$ & .09 \\
\hline Sexual abuse & .15 & .33 & .19 & .36 & $0-1$ & $2.13 *$ \\
\hline Impulsivity & 1.66 & .62 & 1.82 & .64 & $1-4$ & $21.76^{* * *}$ \\
\hline Shyness & 2.79 & 1.18 & 3.13 & 1.24 & $1-5$ & $27.03 * * *$ \\
\hline Harmonious sexual passion & 3.57 & .71 & 3.65 & .74 & $1-5$ & $4.26^{*}$ \\
\hline Obsessive sexual passion & 2.42 & .81 & 2.09 & .80 & $1-5$ & $56.89 * * *$ \\
\hline Inhibited sexual passion & 2.22 & .76 & 2.22 & .78 & $1-5$ & .01 \\
\hline
\end{tabular}

$F$-values for attachment anxiety, attachment avoidance, and sexual abuse were assessed with the WelchSatterthwaite method to account for violating the homogeneity of variance assumption

${ }^{*} p<.05 ; * * p<.01 ; * * * p<.001$ preference for playing with peers. In this study, Cronbach's alpha was .94 for women and .93 for men.

\section{Data Analysis Plan}

To explore gender differences for our variables of interest, we first conducted a MANOVA to assess differences across gender (Table 1). Because there were significant gender differences, we then assessed the bivariate associations between the variables of interest for each gender and created a correlation matrix that was separated by gender (Table 2).

Before evaluating the full structural model, we tested for measurement invariance to assess whether it would be more appropriate to conduct a multi-group analysis by gender or to estimate the models separately. We found that the obsessive sexual passion had no level of invariance. Furthermore, harmonious and inhibited sexual passion only reached weak invariance (full results available at https://osf.io/5zveq/). Models require at least strong invariance to make direct multigroup comparisons (Dyer, 2015; Little, 2013). Considering the lack of measurement invariance, we decided that it would be most appropriate to estimate separate models for each gender rather than grouping them together or making direct comparisons through a multi-group model.

We next explored through a series of structural equation models how relationship characteristics, childhood abuse, attachment style, and personality characteristics predicted the various types of sexual passion when all variables are considered simultaneously. This evaluation allowed us to control for the shared variance among the varying indicators of sexual passion and explore unique associations for each dimension of the predictor variables. Final results are shown in Figs. 1 and 2.
Although error terms were included for each of the endogenous variables listed in the figure, they were not drawn into the figure for the sake of parsimony. The estimation of the models was conducted with AMOS version 23.0 (Arbuckle, 2014).

\section{Results}

\section{Descriptive Statistics}

Gender differences were explored for all the variables. A multivariate analysis of variance (MANOVA) revealed an overall significant gender difference, $F(14,1397)=19.26, p<.001$, partial eta-square $=.16$. Levene's test suggested that homogeneity of variance was violated for physical abuse $(p=.02)$, sexual abuse $(p<.001)$, avoidant attachment $(p=.001)$, and anxious attachment $(p<.001)$. Accordingly, a follow-up with the Welch-Satterthwaite method was conducted to assess the difference between men and women for variables that violated the assumption. Table 1 shows means, standard deviations, and $F$ values for each variable. Men reported significantly higher sexual desire $(p<.01)$, sexual drive $(p<.001)$, and obsessive sexual passion $(p<.001)$. Women reported significantly higher avoidant attachment $(p<.05)$, sexual abuse $(p<.05)$, shyness $(p<.001)$, and harmonious sexual passion $(p<.05)$.

\section{Bivariate Associations}

Because of extensive gender differences between the variables (see Table 1), bivariate correlations were estimated for both men and women to preliminarily assess associations between variables of interest (all associations presented in Table 2). The correlations between the variables were generally as anticipated 


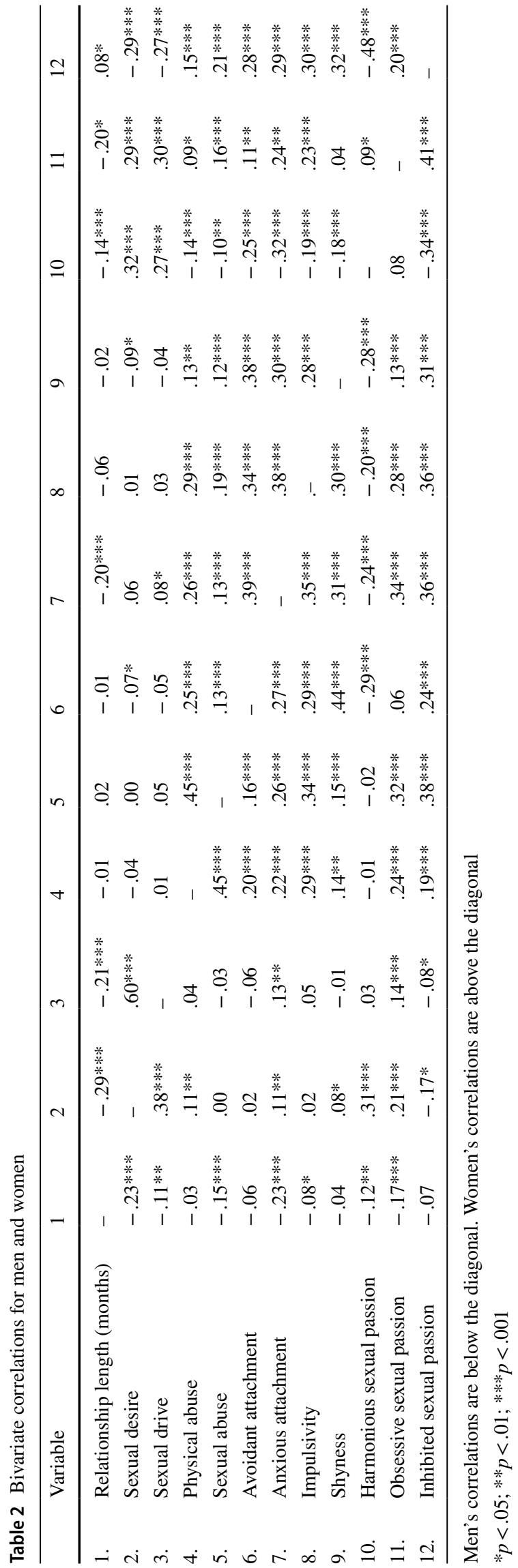

in our hypotheses, with a few exceptions that will be presented later as part of the results for the SEM.

\section{Structural Equation Model}

We then estimated structural equation models (one with 771 women, the other with $643 \mathrm{men}$ ) to evaluate the associations simultaneously in order to take into account the shared variance between these interrelated factors. The model fit was acceptable (Kline, 2016) for both men $\left(\chi^{2}(345)=771.03, \mathrm{CFI}=.95\right.$, RMSEA $=.04, p<.001)$ and women $\left(\chi^{2}(345)=874.88\right.$, $\mathrm{CFI}=.95$, RMSEA $=.05, p<.001)$, and explained moderate variance for both women and men: women harmonious sexual passion $\left(R^{2}=.30\right)$, women obsessive sexual passion $\left(R^{2}=.25\right)$, women inhibited sexual passion $\left(R^{2}=.38\right)$, men harmonious sexual passion $\left(R^{2}=.29\right)$, men obsessive sexual passion $\left(R^{2}=.29\right)$, and men inhibited sexual passion $\left(R^{2}=.38\right)$.

\section{Women}

For women, relationship length was significantly associated with lower harmonious sexual passion $(\beta=-.13, p<.001)$ and lower obsessive sexual passion $(\beta=-.10, p<.01)$, but was unrelated to inhibited sexual passion $(\beta=.04, p=.28)$. Sexual desire was significantly associated with higher harmonious sexual passion $(\beta=.23, p<.001)$, higher obsessive sexual passion $(\beta=.18, p<.001)$, and lower inhibited sexual passion $(\beta=-.20, p<.001)$. Sexual drive was associated with higher harmonious sexual passion $(\beta=.15, p<.001)$, higher obsessive sexual passion $(\beta=.15, p<.001)$, and lower inhibited sexual passion $(\beta=-.21, p<.001)$.

In contrast to the correlations, in the full model physical abuse was no longer significantly associated with harmonious sexual passion $(\beta=-.01, p=.93)$, obsessive sexual passion $(\beta=.04$, $p=.41)$, or inhibited sexual passion $(\beta=.00, p=.93)$. Also, sexual abuse was not significantly associated with harmonious sexual passion $(\beta=-.06, p=.14)$. However, sexual abuse was significantly associated with higher obsessive sexual passion $(\beta=.09, p=.03)$ and inhibited sexual passion $(\beta=.15, p<.001)$.

Avoidant attachment was not associated with obsessive sexual passion $(\beta=.05, p=.22)$, but was significantly associated with higher inhibited sexual passion $(\beta=.09, p=.03)$ and lower harmonious sexual passion $(\beta=-10, p=.01)$. Also, anxious attachment was associated with lower harmonious sexual passion $(\beta=-.32, p<.001)$ and higher inhibited sexual passion $(\beta=.18, p<.001)$, but was not associated with higher obsessive sexual passion $(\beta=.08, p=.07)$.

Impulsivity was associated with higher inhibited sexual passion $(\beta=.12, p<.01)$ and obsessive sexual passion $(\beta=.27$, $p<.001)$, but was not associated with harmonious sexual passion $(\beta=-.00, p=.99)$. Shyness was associated with higher inhibited sexual passion $(\beta=.22, p<.001)$, yet was not associated with obsessive sexual passion $(\beta=-.06, p=.10)$ or 
Fig. 1 Women's model assessing the association between relationship factors, attachment security, childhood abuse, and personality with harmonious, obsessive, and inhibited sexual passion. For parsimony, only significant structural paths are displayed. $\chi^{2}(345)=874.88$, $\mathrm{CFI}=.95$, RMSEA $=.05$, $p<.001, * p<.05, * * p<.01$, $* * * p<.001$

Fig. 2 Men's model assessing the association between relationship factors, attachment security, childhood abuse, and personality with harmonious, obsessive, and inhibited sexual passion. For parsimony, only significant structural paths are displayed. $\chi^{2}(345)=771.03$, $\mathrm{CFI}=.95$, $\mathrm{RMSEA}=.04$, $p<.001, * p<.05, * * p<.01$, $* * * p<.001$
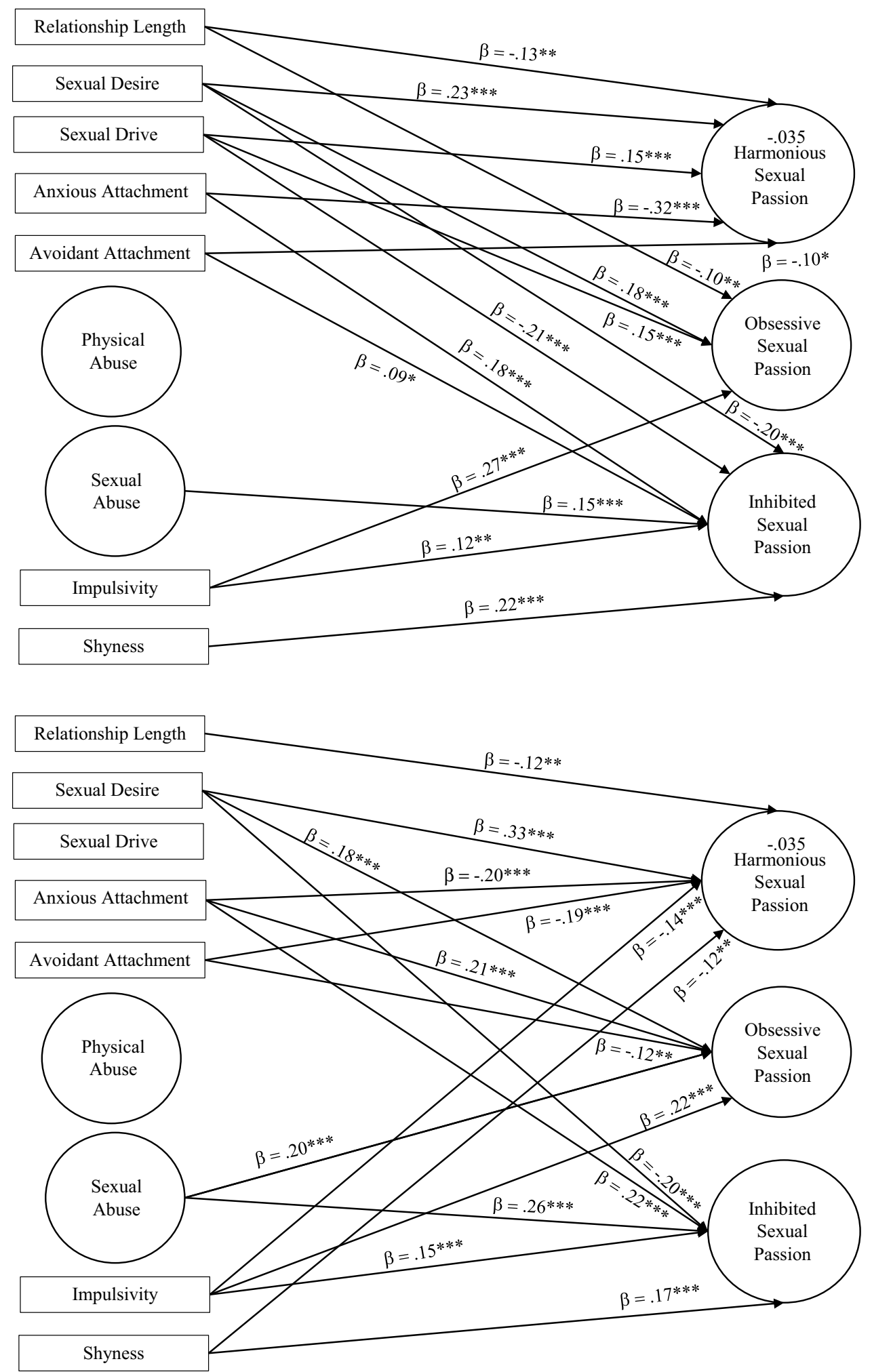

harmonious sexual passion $(\beta=-.05, p=.20)$. Results are shown in Fig. 1.
Men

For men, relationship length was significantly associated with lower harmonious sexual passion $(\beta=-.12, p<.01)$, but was unrelated to inhibited sexual passion $(\beta=.02, p=.66)$ or 
obsessive sexual passion $(\beta=-.03, p=.46)$. Sexual desire was significantly associated with higher harmonious sexual passion $(\beta=.33, p<.001)$ and higher obsessive sexual passion $(\beta=.18, p<.001)$, but lower inhibited sexual passion $(\beta=-.20$, $p<.001)$. Sexual drive was unrelated to harmonious sexual passion $(\beta=-.07, p=.08)$, obsessive sexual passion $(\beta=-.00$, $p=.96)$, and inhibited sexual passion $(\beta=-.07, p=.08)$.

In contrast to the correlations, in the full model physical abuse was no longer significantly associated with harmonious sexual passion $(\beta=.04, p=.45)$, obsessive sexual passion $(\beta=.08, p=.11)$, or inhibited sexual passion $(\beta=.01, p=.81)$. Also, sexual abuse was not significantly associated with harmonious sexual passion $(\beta=.07, p=.14)$. However, sexual abuse was significantly associated with higher obsessive sexual passion $(\beta=.20, p<.001)$, andinhibited sexualpassion $(\beta=.26$, $p<.001)$.

Avoidant attachment was not associated with inhibited sexual passion $(\beta=. .08, p=.06)$, but was significantly associated with lower obsessive sexual passion $(\beta=-.12, p<.01)$ and lower harmonious sexual passion $(\beta=-.19, p<.001)$. Also, anxious attachment was associated with lower harmonious sexual passion $(\beta=-.20, p<.001)$, higher inhibited sexual passion $(\beta=.22, p<.001)$, and higher obsessive sexual passion $(\beta=.21$, $p<.001)$.

Impulsivity was associated with higher inhibited sexual passion $(\beta=.15, p<.001)$ and obsessive sexual passion $(\beta=.22$, $p<.001)$, and also was associated with lower harmonious sexual passion $(\beta=-.14, p<.001)$. Shyness was associated with lower harmonious sexual passion $(\beta=-.12, p<.01)$, higher inhibited sexual passion $(\beta=.17, p<.001)$, yet was not associated with obsessive sexual passion $(\beta=.03, p=.52)$. Results are shown in Fig. 2.

\section{Discussion}

Sexual passion expression has been shown to be highly correlated with satisfactory relationships (Busby et al., 2019a, b). Now researchers and practitioners can see some of the substantial predictors of sexual passion expression in committed relationships, as several of the relationship and individual factors were important predictors of the distinct types of sexual passion expression. Overall, those with higher sexual desire, secure attachment, no childhood abuse, and low impulsivity and shyness were most likely to develop optimal sexual passion (higher harmonious, lower inhibited, and lower obsessive sexual passion). These results provide a good starting point for more thoroughly understanding the Triadic Model of Sexual Passion. They also highlight some of the complex nuances in how a variety of factors may differentially predict these aspects of sexual passion expression.

\section{Relationship Factors}

The first portion of our first hypothesis (H1a) was not supported. Although the bivariate correlation coefficient suggested that obsessive sexual passion may be more negatively correlated with relationship length than harmonious sexual passion, when all the variables were evaluated simultaneously, harmonious sexual passion retained a negative association with relationship length. This finding may have occurred because harmonious sexual passion is tied to the strength of the relationship as a whole and to sexual desire (Busby et al., 2019a). Because relationship satisfaction (Anderson, Van Ryzin, \& Doherty, 2010) and sexual desire (e.g., Graham et al., 2017; Klusmann, 2002) in the average relationship tend to decline over time, it makes sense that harmonious sexual passion could decline as well. Maintaining healthy sexual passion is likely possible, but perhaps only a limited number of couples manage to do so. The associations between relationship length and the other variables were moderate to small and should not be overemphasized. Still, researchers might consider evaluating the role of maintaining high overall relationship quality (Anderson et al., 2010) and focusing attention on meeting a partner's sexual needs (Muise, Impett, Kogan, \& Desmarais, 2013) in retaining harmonious sexual passion over time.

The second (H1b) portion of our first hypothesis was supported, as sexual desire directed toward the partner was correlated with higher harmonious sexual passion, higher obsessive sexual passion, and lower inhibited sexual passion. Considering that a small degree of obsessive passion does not appear to be particularly harmful to relationships (Busby et al., 2019a, b; Vallerand, 2015), sexual desire toward a partner seems to be a positive predictor of healthy sexual passion in a relationship.

The third (H1c) portion of our first hypothesis provided a more complicated picture. Our general assertion that sexual drive might be less adaptive than sexual desire in predicting optimal passion development was supported. But there were some cases that had different patterns of associations for women and men. Sexual drive was not particularly adaptive for men, as the bivariate correlations revealed a positive correlation with obsessive sexual passion, and the SEM model revealed no association between sexual drive and any type of passion. Meanwhile, although not as positive as sexual desire toward their partners, sexual drive seemed somewhat conducive to optimal sexual passion expression for women, as it was associated with higher harmonious sexual passion, higher obsessive sexual passion, and lower inhibited sexual passion. Interesting to note is that the way women think about sexual drive was more highly correlated with sexual desire toward her partner than men's sexual drive was correlated with sexual desire toward his partner. It seems that men and women are thinking about the construct for sexual drive in diverse ways that cannot be fully differentiated in our study. Men's clear differentiation between sexual drive and sexual desire toward a partner suggests that their sexual 
drive is not solely based on their sexual relationship with their partner. Meanwhile, when women answered the question for sexual drive, the lack of differentiation between sexual desire and sexual drive toward a partner suggests that they are likely still thinking of sexual drive in a relational context.

Overall, the somewhat modest correlations between the sexual desire variables and the sexual passion variables highlight their distinction. There appears to be a growing consensus that some level of sexual desire is something of a prerequisite for sexual passion (Philippe et al., 2017). However, much remains to be understood about the relationship between sexual desire and sexual passion. Perhaps future researchers can specifically evaluate low sexual desire participants to assess some of their patterns for sexual passion expression variables.

\section{Attachment Security}

The first portion of our second hypothesis (H2a) was supported, as those with anxious attachment reported lower harmonious sexual passion, and higher obsessive and inhibited sexual passion. This supports previous literature suggesting the ambivalent nature of sexual difficulties for those higher in anxious attachment. They seem to struggle in finding the right level of closeness, alternating between more obsessive sexuality, and more inhibited sexuality (Mikulincer \& Shaver, 2016). Women's anxious attachment, however, was unrelated to obsessive sexual passion in the final model, suggesting other variables in the model (possibly sexual desire and/or sexual drive) may mediate or moderate the association between women's anxious attachment and obsessive sexual passion.

The second portion of our second hypothesis was generally supported (H2b), as those with higher avoidance reported lower harmonious sexual passion and higher inhibited sexual passion. Interesting to note is that the association between avoidance and inhibited sexual passion vanished when all the variables were assessed simultaneously. This suggests that some of the other variables in the analysis (e.g., sexual desire) may serve as mechanisms that explain why those with an avoidant attachment are more likely to report inhibited sexual passion. Nonetheless, these results seem to support previous research suggesting that those who score high on avoidant attachment have a higher fear of intimacy (Doi \& Thelan, 1993) and inhibited self-disclosure (Collins, Cooper, Albino, \& Allard, 2002).

These findings should be of note to therapists working with people struggling with their sexual relationship. While additional research is needed to better understand the directionality of the association between attachment security and sexual passion, theory suggests that attachment security could be an important catalyst to optimal passion development (Mikulincer \& Shaver, 2016). Perhaps future researchers might consider the mediating role of sexual passion between attachment security and sexual satisfaction. This could inform lay people and therapists of multiple potential intervention points in helping individuals experience more satisfaction intheir sexualrelationships.

\section{Childhood Abuse}

As hypothesized (H3a), both physical abuse and sexual abuse were positively correlated with obsessive sexual passion and inhibited sexual passion. However, they were only negatively correlated with women's harmonious sexual passion. This supportsprevious research suggesting that child abuse is related to more difficulties in a sexual relationship, by means of both moreinhibition and hyperactivation of the sexual behavioral system. (Seehuus et al., 2015; Vaillancourt-Morel et al., 2015). However, as hypothesized (H3b), once physical and sexual abuse were evaluated together, physical abuse was a less important predictor than sexual abuse; in fact, it lost significance entirely. This supports the notion that abuse happening in the sexual domain is more likely to influence the sexual relationship than other types of abuse (Seehuus et al., 2015). Also interesting to note is that sexual abuse was not significantly associated with harmonious sexual passion in the final SEMs, and was also unrelated to women's obsessive sexual passion. Perhaps, the reason for lower associations is sexual abuse's correlational overlap with the attachment constructs (see Table 2). It would be profitable for future research to assess whether sexual abuse may lead to less adaptive sexual passion in connection with its potential to hurt attachment security, as the two constructs have been connected in previous research (Mikulincer \& Shaver, 2016).

Although we cannot definitively speak to differences between women and men due to the lack of measurement invariance, it is interesting to note that men who were victims of sexual abuse had an association with both higher obsessive and inhibited sexual passion, whereas women only reported an association with higher inhibited sexual passion. Future research is needed, but this may be a result of stigma surrounding male victims of sexual abuse, which perhaps leads to lower likelihood of seeking help in addressing past trauma (e.g., Price-Robertson, 2012). Overall, while the bivariate correlations suggested that physical abuse seems to be problematic for developing optimal sexual passion, its loss of significance in the full SEM models suggests the importance of specifically considering the sexual domain for how abuse may influence the development of passion. It is noteworthy that a factor as distal as sexual abuse retained significance in the final model, although many important factors were accounted for in the prediction of sexual passion expression. This suggests that this is one of many factors therapists may consider inquiring after if clients have trouble expressing their sexual passion in an optimal matter. 


\section{Personality}

Our hypotheses ( $\mathrm{H} 4 \mathrm{a}$ and $\mathrm{H} 4 \mathrm{~b}$ ) were generally supported, as impulsivity was associated with higher obsessive sexual passion, and shyness was associated with higher inhibited sexual passion. The results, however, revealed other nuances and unexpected findings. Although both impulsivity and shyness were related to lower harmonious sexual passion in the bivariate correlations, the only association that retained significance in the final SEM was the negative association between men's shyness and harmonious sexual passion. This finding is consistent with past research suggesting shyness is problematic for men's life outcomes (Rowsell \& Coplan, 2013). Overall, like the muted association between avoidant attachment and inhibited sexual passion when moving from bivariate analyses to a SEM framework, this suggests that other variables may be mechanisms that could explain why impulsivity and shyness are associated with lower harmonious sexual passion.

As hypothesized, individuals who are shy seem to approach sexual passion with more inhibition, likely a result of generally having an overcontrolled personality orientation that inhibits autonomous growth (Rubin \& Asendorpf, 1993). Additionally, finding that impulsivity was associated with higher obsessive sexual passion lined up with previous research, as impulsivity is generally linked to undercontrol (Eisenberg et al., 2007), and obsessive passion has been theoretically related to undercontrol of a passion (Vallerand, 2015). However, an unexpected finding was that impulsivity was also related to higher inhibited sexual passion. Future research should evaluate the reason for this unexpected finding. Perhaps those who are impulsive may occasionally be rash in displaying their sexual passion. In turn, this rash display of sexual passion may result in a poor sexual experience that leaves them struggling to know how to properly express their passion. Perhaps impulsivity can lead to a conflict in knowing how to properly express passion, where individuals have both higher obsessive and inhibited passion. But these thoughts are speculatory and require additional research.

Personality may be a challenging intervention point in helping people develop optimal sexual passion, as personality is known to be highly stable over time (e.g., Edmonds, Goldberg, Hampson, \& Barckley, 2013; Hampson \& Goldberg, 2006). However, there is some evidence (albeit in childhood) that not overprotecting individuals with an inhibited temperament might help them to better adapt to their inhibitions (Johnson et al., 2016). More directly, some research has suggested that a strong desire to engage in sexual activity can help in overcoming inhibitions (Birnbaum et al., 2014). While much research is still required on this subject, it seems plausible that careful scaffolding could help individuals whose personalities are naturally inclined toward either obsessive or inhibited sexual passion.

\section{Limitations and Future Directions}

Our study had strengths such as a large sample size, advanced analyses, and advancing theoretical and empirical understandings of sexual passion expression as a construct of interest. Still, our study had limitations. One was the use of cross-sectional data, which precludes directional and causal conclusions. For example, sexual desire may lead to development of more harmonious sexual passion. Or the development of harmonious sexual passion may lead to sexual partners feeling higher sexual desire toward each other. Future research should assess these associations longitudinally to better establish directionality and to the extent possible experimentally to assess causality (e.g., Philippe et al., 2017). Another limitation was the use of a Mechanical Turk as a nonrepresentative sampling frame (Peer et al., 2014). Although we increased confidence in the validity of our data through our cleaning procedures, researchers should attempt to replicate these findings in other samples. Another major limitation of the study was the lack of dyadic data. This is a particularly problematic for the relationship factors as we were unable to fully assess couple processes that may be more conducive to the development of sexual passion. Considering that men's sexual desire seemed a particularly strong predictor of men's harmonious sexual passion, examining more specific couple processes is likely a profitable area of future research. It would be particularly profitable for future research to assess these associations with dyadic data over time.

Another limitation was the use of one item measurement for sexual desire toward a partner and sexual drive. The sexual desire toward a partner measure is particularly problematic for those who might be in a same-sex relationship (though our sample only had $2.4 \%$ of participants report a same-sex sexual preference). In future research, it would be beneficial to analyze facets of sexual desire more comprehensively, as well as more comprehensively assess different relationship configurations.

Due to the exploratory nature of this study, we chose to evaluate several theoretically key factors in the development of sexual passion. One benefit of this is that it opens a profitable area of future research, as many of these variables may work together as explanatory mechanisms, or potentially moderate the variables accounted for. Our variables may be uniquely intertwined in the development of sexual passion. In just one previously mentioned example, perhaps attachment security may intertwine with sexual desire and/or sexual abuse as either a mediator or moderator for sexual passion. Additionally, we might ask whether passion expression has differing associations with relationship outcomes for people who are higher in anxious or avoidant attachment.

The results from this study add confidence to the growing body of research validating the utility of these scales. But as with any relatively new measure, there are only so many related constructs we can validate this scale with at any given time. 
It would be beneficial for future research to psychometrically compare these passion scales to sexuality scales on excitation and inhibition (Graham, Sanders, \& Milhausen, 2006; Milhausen, Graham, Sanders, Yarber, \& Maitland, 2010). Though these types of scales have overlap, there is conceptual distinction, as our sexual passion measures are more relational and psychological phenomenon, while the sexual excitation and inhibition scales focus more on physical function and arousal.

In our explorations, we found some noticeably different patterns for the associations in this study between women and men. But the lack of measurement invariance keeps us from direct statistical comparisons. For example, just because shyness for men predicted lower harmonious sexual passion and shyness forwomen did not predict harmonious sexual passion, itwould be inaccurate to say that men's shyness morestrongly predicts harmonious sexual passion than women's shyness. This is because we are notsure whether finding a significant association for men and not for women is actually due to the connection between shyness and harmonious sexual passion or is due to men and women having a different understanding of what harmonious sexual passion is. This lack of measurement invariance deserves attention as both a limitation and future direction. Measurement invariance is becoming a more commonly used test to highlight the psychometric utility of scales, particularly ensuring invariance between women and men (e.g., Bőthe et al., 2018; Dyar, Feinstein, \& Davila, 2019; Eaton \& Matamala, 2014). At the same time, a recent review suggested we should view measurement invariance with more nuance than as a nuisance checkbox for psychometric validity (Sakaluk, 2019). A scale not being invariant across gender may make theoretical sense. In a recent study, multiple measures of sexual media use failed to reach invariance between women and men (Leonhardt \& Willoughby, 2019), which is understandable considering large difference in sexual media use patterns between women and men (Carroll, Busby, Willoughby, \& Brown, 2017). Invariance testing does not have to stop at gender either. Sakaluk (2019) highlighted that although a sexual compulsivity scale (Kalichman \& Rompa, 1995) was found to have gender invariance, more advanced analyses showed it did not have invariance across age. In other words, diving deeper into gender invariance may just be the beginning in understanding psychometrics of scales. In the case of the constructs for sexual passion expression, it would be beneficial to dive more deeply into items are not invariant across gender. Researchers can build off that and test whether invariance is reached across age and culture and question why or why not. As we continue to emphasize, this study focuses on constructs that have only just been developed. The evidence so far suggests they are psychometrically sound constructs for both men and women, but additional work can be done to increase confidence in their validity.

\section{Conclusion}

Research on passion expression has risen tremendously over the past couple of decades (Vallerand, 2015; Vallerand et al., 2003). A rich body of work now evinces the benefits of optimal passion expression in a variety of domains (Vallerand, 2015). This study is one of the few to apply this body of the literature specifically to the domain of sexuality. Research is emerging on how these constructs are valuable predictors of both sexual and relational outcomes both individually and dyadically (Busby et al., 2019b). This study builds on that by connecting sexual passion constructs to a number of related predictors. Though bivariate assessment of these variables have been assessed previously (e.g., relationship duration and sexual desire; attachment and sexual outcomes), this is the first study to establish such links with these new constructs for sexual passion expression.

Many factors are yet to be identified in the development of sexual passion, as our model explained variances ranging from $25 \%$ (i.e., women's obsessive sexual passion) to $38 \%$ (i.e., men's inhibited sexual passion) for the variables of interest. These constructs of sexual passion expression are young in their development. It will be worthwhile to better understand measurement invariance and how they more fully are differentiated from other related constructs. At the same time, this study provides an important beginning step in empirically testing factors involved in developing optimal sexual passion in a committed relationship. There are limitations of what we can conclude from one cross-sectional, correlational study, but this study plays a crucial role in opening the gate to further inquiry. By continuing to evaluate how sexual passion expression intertwines with a variety of predictors, we hope more researchers, practitioners, and couples will reap the benefits of understanding how to better develop and sustain a harmoniously passionate sexual relationship (Busby et al., 2019a, b).

Acknowledgements We would like to thank Dr. Larry Nelson for conceptual feedback and Dr. Alexander Jensen for the helpful review of earlier drafts.

Funding Funding for the current study came from an internal research grant from the second author's university.

\section{Compliance with Ethical Standards}

Conflict of interest The authors declare that they do not have any conflicts of interest.

Ethical Approval All procedures performed in studies involving human participants were in accordance with the ethical standards of the institutional research committee and with the 1964 Helsinki Declaration and its later amendments.

Informed Consent Informed consent was obtained for all individual participants in the study. 


\section{References}

Acevedo, B. P., \& Aron, A. (2009). Does a long-term relationship kill romantic love? Review of General Psychology,13(1), 59-65. https ://doi.org/10.1037/a0014226.

Anderson, J. R., Van Ryzin, M. J., \& Doherty, W. J. (2010). Developmental trajectories of marital happiness in continuously married individuals: A group-based modeling approach. Journal of Family Psychology, 24(5), 587-596. https://doi.org/10.1037/a0020928.

Arbuckle, J. L. (2014). Amos 23.0 user's guide. Chicago, IL: SPSS.

Aron, A., \& Aron, E. (1986). Love and the expansion of self: Understanding attraction and satisfaction. New York: Hemisphere.

Asendorpf, J. B., Denissen, J. J. A., \& van Aken, M. A. G. (2008). Inhibited and aggressive preschool children at 23 years of age: Personality and social transitions into adulthood. Developmental Psychology, 44(4), 997-1011. https://doi.org/10.1037/0012-1649.44.4.997.

Bai, H. (2018). Evidence that a large amount of low quality responses on MTurk can be detected with repeated GPS coordinates. Retrieved from: https://www.maxhuibai.com/blog/evidence-that-responsesfrom-repeating-gps-are-random.

Bernstein, D. P., Fink, L., Handelsman, L., Foote, J., Lovejoy, M., Wenzel, K., ... Ruggiero, J. (1994). Initial reliability and validity of a new retrospective measure of child abuse and neglect. American Journal of Psychiatry, 151(8), 1132-1136. https://doi.org/10.1176/ ajp.151.8.1132.

Birnbaum, G. E., Mikulincer, M., Szepsenwol, O., Shaver, P. R., \& Mizrahi, M. (2014). When sex goes wrong: A behavioral systems perspective on individual differences in sexual attitudes, motives, feelings, and behaviors. Journal of Personality and Social Psychology, 106(5), 822-842. https://doi.org/10.1037/a0036021.

Bogaert, A. F. (2004). Asexuality: Prevalence and associated factors in a national probability sample. Journal of Sex Research, 41, 279-287.

Bőthe, B., Tóth-Király, I., Zsila, A., Griffiths, M. D., Demetrovics, Z., \& Orosz, G. (2018). The development of the Problematic Pornography Consumption Scale (PPCS). Journal of Sex Research, 55, 395-406.

Brotto, L. A., \& Smith, K. B. (2014). Sexual desire and pleasure. In D. L. Tolman, L. M. Diamond, J. A. Bauermeister, W. H. George, J. G. Pfaus, \& L. M. Ward (Eds.), APA handbook of sexuality and psychology, Person-based approaches (Vol. 1, pp. 205-244). Washington, DC: American Psychological Association. https:// doi.org/10.1037/14193-008.

Busby, D. M., Chiu, L. H., Leonhardt, N. D., \& Iliff, E. (2019a). Sexual passion in committed relationships: Measurement and conceptual issues. Family Process, 58(3), 734-748.

Busby, D. M., Leonhardt, N. D., \& James, S. L. (2019b). A closer look at sexual passion in a relationship. Journal of Child \& Family Studies. https://doi.org/10.1007/s10826-019-01682-4.

Carbonneau, N., Vallerand, R. J., Lavigne, G. L., \& Paquet, Y. (2016). "I'm not the same person since I met you": The role of romantic passion in how people change when they get involved in a romantic relationship. Motivation and Emotion, 40(1), 101-117. https://doi. org/10.1007/s11031-015-9512-z.

Carnelley, K. B., \& Ruscher, J. B. (2000). Adult attachment and exploratory behavior in leisure. Journal of Social Behavior \& Personality, 15(2), 153-165.

Carroll, J. S., Busby, D. M., Willoughby, B. J., \& Brown, C. C. (2017). The porn gap: Differences in men's and women's pornography patterns in couple relationships. Journal of Couple \& Relationship Therapy, 16, 146-163.

Coplan, R. J., Prakash, K., O’Neil, K., \& Armer, M. (2004). Do you 'want' to play? Distinguishing between conflicted-shyness and social disinterest in early childhood. Developmental Psychology, 40(2), 244-258. https://doi.org/10.1037/0012-1649.40.2.244.

Collins, N. L., Cooper, M. L., Albino, A., \& Allard, L. (2002). Psychosocial vulnerability from adolescence to adulthood: A prospective study of attachment style differences in relationship functioning and partner choice. Journal of Personality, 70(6), 965-1008.

Doi, S. C., \& Thelen, M. H. (1993). The Fear-of-Intimacy Scale: Replication and extension. Psychological Assessment, 5(3), 377-383.

Dyar, C., Feinstein, B. A., \& Davila, J. (2019). Development and validation of a brief version of the Anti-Bisexual Experiences Scale. Archives of Sexual Behavior, 48, 175-189.

Dyer, W. J. (2015). The vital role of measurement equivalence in family research. Journal of Family Theory \& Review, 7(4), 415-431. https ://doi.org/10.1111/jftr.12115.

Eaton, A. A., \& Matamala, A. (2014). The relationship between heteronormative beliefs and verbal sexual coercion in college students. Archives of Sexual Behavior, 43, 1443-1457.

Edmonds, G. W., Goldberg, L. R., Hampson, S. E., \& Barckley, M. (2013). Personality stability from childhood to midlife: Relating teachers' assessments in elementary school to observer- and selfratings 40 years later. Journal of Research in Personality, 47(5), 505-513. https://doi.org/10.1016/j.jrp.2013.05.003.

Eisenberg, N., Ma, Y., Chang, L., Zhou, Q., West, S. G., \& Aiken, L. (2007). Relations of effortful control, reactive undercontrol, and anger to Chinese children's adjustment. Developmental and Psychopathology, 19(2), 385-409. https://doi.org/10.1017/s0954 579407070198.

Elliott, S., \& Umberson, D. (2008). The performance of desire: Gender and sexual negotiation in long-term marriages. Journal of Marriage and Family, 70(2), 391-406. https://doi.org/10.111 1/j.1741-3737.2008.00489.x.

Graham, C. A., Mercer, C. H., Tanton, C., Jones, K. G., Johnson, A. M., Wellings, K., \& Mitchell, K. R. (2017). What factors are associated with reporting lacking interest in sex and how do these vary by gender? Findings from the third British National Survey of Sexual Attitudes and Lifestyles. British Medical Journal Open, 7 , 3016942. https://doi.org/10.1136/bmjopen-2017-016942.

Graham, C. A., Sanders, S. A., \& Milhausen, R. R. (2006). The Sexual Excitation/Sexual Inhibition Inventory Women: Psychometric properties. Archives of Sexual Behavior, 35, 397-409.

Griffin, D., \& Bartholomew, K. (1994). Models of the self and other: Fundamental dimensions underlying measures of adult attachment. Journal of Personality and Social Psychology, 67, 430-445.

Hampson, S. E., \& Goldberg, L. R. (2006). A first large cohort study of personality trait stability over the 40 years between elementary school and midlife. Journal of Personality and Social Psychology, 91(4), 763-779. https://doi.org/10.1037/0022-3514.91.4.763.

Hatfield, E., \& Rapson, R. L. (1990). Passionate love in intimate relationships. In B. S. Moore \& A. M. Isen (Eds.), Stueis in emotion and social interaction: Affect and social behavior (pp. 126-151). New York: Cambridge University Press.

Hatfield, E., \& Rapson, R. (1993). Love and attachment processes. In M. Lewis \& J. M. Haviland (Eds.), Handbook of emotions (pp. 595-604). New York: Guilford Press.

Ho, V. T., Wong, S. S., \& Lee, C. H. (2011). A tale of passion: Linking job passion and cognitive engagement to employee work performance. Journal of Management Studies, 48(1), 26-47. https://doi. org/10.1111/j.1467-6486.2009.00878.x.

Johnson, J. C., Olino, T. M., Klein, D. N., Dyson, M. W., Bufferd, S. J., Durbin, C. E., ... Hayden, E. P. (2016). A longitudinal investigation of predictors of the association between age 3 and age 6 behavioural inhibition. Journal of Research in Personality, 63, 51-61. https://doi.org/10.1016/j.jrp.2016.04.008.

Kalichman, S. C., \& Rompa, D. (1995). Sexual sensation seeking and sexual compulsivity scales: Validity, and predicting HIV risk behavior. Journal of Personality Assessment, 65, 586-601.

Katz-Wise, S. L., \& Hyde, J. S. (2014). Sexuality and gender: The interplay. In D. Tolman, L. Diamond, J. Bauermeister, W. George, J. Pfaus, \& L. Ward (Eds.), APA handbook of sexuality and 
psychology: Person-based approaches (Vol. 1, pp. 31-62). Washington, DC: American Psychological Association.

Kim, J., \& Hatfield, E. (2004). Love types and subjective well-being: A cross-cultural study. Social Behavior and Personality, 32(2), 173-182. https://doi.org/10.2224/sbp.2004.32.2.173.

Kinsey, A. C., Pomeroy, W. B., \& Martin, C. E. (1948). Sexual behavior in the human male. Bloomington: Indiana University Press.

Kline, R. B. (2016). Principles and practice of structural equation modeling. New York, NY: Guilford Press.

Klusmann, D. (2002). Sexual motivation and the duration of partnership. Archives of Sexual Behavior, 31, 275-287.

Leonhardt, N. D., \& Willoughby, B. J. (2019). Pornography, provocative sexual media, and their differing associations with multiple aspects of sexual satisfaction. Journal of Social and Personal Relationships, 36, 618-641.

Levine, S. B. (1987). More on the nature of sexual desire. Journal of Sex and Marital Therapy, 13(1), 35-44. https://doi.org/10.1080/00926 238708403877.

Little, T. D. (2013). Longitudinal structural equation modeling. New York: The Guilford Press.

Luster, S. S., Nelson, L. J., Poulsen, F. O., \& Willoughby, B. J. (2013). Emerging adult sexual attitudes and behaviors: Does shyness matter? Emerging Adulthood, 1(3), 185-195. https://doi. org/10.1177/2167696813475611.

Mikulincer, M., \& Shaver, P. R. (2016). Attachment in adulthood, second edition: Structure, dynamics, and change. New York, NY: The Guilford Press.

Mikulincer, M., Shaver, P. R., \& Solomon, Z. (2015). An attachment perspective on traumatic and post-traumatic reactions. In M. P. Safir, H. S. Wallach, \& S. Rizzo (Eds.), Future directions in posttraumatic stress disorder: Prevention, diagnosis, and treatment (pp. 79-96). New York: Springer Press.

Milhausen, R. R., Graham, C. A., Sanders, S. A., Yarber, W. L., \& Maitland, S. B. (2010). Validation of the Sexual Excitation/Sexual Inhibition Inventory for Women and Men. Archives of Sexual Behavior, 39, 1091-1104.

Muise, A., Impett, E. A., Kogan, A., \& Desmarais, S. (2013). Keeping the spark alive: Being motivated to meet a partner's sexual needs sustains sexual desire in long-term romantic relationships. Social Psychological and Personality Science, 4(3), 267-273. https://doi. org/10.1177/1948550612457185.

Nelson, L. J., Padilla-Walker, L. M., Badger, S., Barry, C. M., Carroll, J. S., \& Madsen, S. D. (2008). Associations between shyness and internalizing behaviors, externalizing behaviors, and relationships during emerging adulthood. Journal of Youth and Adolescence, 37(5), 605-615. https://doi.org/10.1007/s10964-007-9203-5.

Paolacci, G., Chandler, J., \& Ipeirotis, P. G. (2010). Running experiments on Amazon Mechanical Turk. Judgment and Decision Making, 5(5), 411-419.

Peer, E., Vosgerau, J., \& Acquisti, A. (2014). Reputation as a sufficient condition for data quality on Amazon Mechanical Turk. Behavior Research Methods, 46(4), 1023-1031. https://doi. org/10.3758/s13428-013-0434-y.

Philippe, F. L., Vallerand, R. J., Bernard-Desrosiers, L., Guilbault, V., \& Rajotte, G. (2017). Understanding the cognitive and motivational underpinnings of sexual passion from a dualistic model. Journal of Personality and Social Psychology, 113, 769-785.

Philippe, F. L., Vallerand, R. J., Beaulieau-Pelletier, G., Maliha, G., LAventure, S., \& Ricard-St-Aubin, R. (2019). Development of a dualistic model of sexual passion: Investigating determinants and consequences. Archives of Sexual Behavior, 48, 2537-2552. https://doi.org/10.1007/s10508-019-1524-w.

Price-Robertson, R. (2012). Child sexual abuse, masculinity and fatherhood. Journal of Family Studies, 18(2-3), 130-142. https ://doi.org/10.5172/jfs.2012.18.2-3.130.
Ratelle, C. F., Carbonneau, N., Vallerand, R. J., \& Mageau, G. (2013). Passion in the romantic sphere: A look at relational outcomes. Motivation and Emotion, 37(1), 106-120. https://doi. org/10.1007/s11031-012-9286-5.

Rowsell, H. C., \& Coplan, R. J. (2013). Exploring links between shyness, romantic relationship quality, and well-being. Canadian Journal of Behavioural Science, 45(4), 287-295. https://doi. org/10.1037/a0029853.

Rubin, K. H., \& Asendorpf, J. B. (Eds.). (1993). Social withdrawal, inhibition and shyness in childhood. Hillsdale, NJ: Erlbaum.

Sakaluk, J. K. (2019). Expanding statistical frontiers in sexual science: Taxometric, invariance, and equivalence testing. Journal of Sex Research, 56, 475-510. https://doi.org/10.1080/00224 499.2019.1568377.

Seehuus, M., Clifton, J., \& Rellini, A. H. (2015). The role of family environment and multiple forms of childhood abuse in the shaping of sexual function and satisfaction in women. Archives of Sexual Behavior, 44(6), 1595-1608. https://doi.org/10.1007/ s10508-014-0364-5.

Simpson, J. A., Rholes, W. S., \& Nelligan, J. S. (1992). Support seeking and support giving within couples in an anxiety-provoking situation: The role of attachment styles. Journal of Personality and Social Psychology, 62, 434-446.

Simpson, J. A., Rholes, S. W., \& Phillips, D. (1996). Conflict in close relationships: An attachment perspective. Journal of Personality and Social Psychology, 71(5), 899-914. https://doi. org/10.1037/0022-3514.71.5.899.

Sternberg, R. J. (1986). A triangular theory of love. Psychological Review, 93(2), 119-153. https://doi.org/10.1037/0033-295X.93.2.119.

Sternberg, R. J. (1988). Triangulating love. In R. J. Sternberg \& M. L. Barnes (Eds.), The psychology of love (pp. 1119-1138). New Haven, CT: Yale University Press.

Suri, S., \& Watts, D. J. (2011). Cooperation and contagion in webbased, networked public goods experiments. PLoS ONE, 8356(3), e16836. https://doi.org/10.1371/journal.pone.0016836.

Tangney, J. P., Baumeister, R. F., \& Boone, A. L. (2004). High selfcontrol predicts good adjustment, less pathology, better grades, and interpersonal success. Journal of Personality, 72(2), 271-324. https://doi.org/10.1111/j.0022-3506.2004.00263.x.

Vaillancourt-Morel, M., Godbout, N., Labadie, C., Runtz, M., Lussier, Y., \& Sabourin, S. (2015). Avoidant and compulsive sexual behaviors in male and female survivors of childhood sexual abuse. Child Abuse and Neglect, 40, 48-59. https://doi.org/10.1016/j. chiabu.2014.10.024.

Vallerand, R. J. (2015). The psychology of passion: A dualistic model. New York, NY: Oxford University Press.

Vallerand, R. J., Blanchard, C., Mageau, G. A., Koestner, R., Ratelle, C. F., Leonard, M., et al. (2003). Les passions de l'a Ame: On obsessive and harmonious passion. Journal of Personality and Social Psychology, 85(4), 756-767. https://doi. org/10.1037/0022-3514.85.4.756.

Vallerand, R. J., Rousseau, F. L., Grouzet, F. M. E., Dumais, A., \& Grenier, S. (2006). Passion in sport: A look at determinants and affective experiences. Journal of Sport \& Exercise Psychology, 28(4), 454-478. https://doi.org/10.1123/jsep.28.4.454.

Vallerand, R. J., \& Verner-Filion, J. (2013). Passion and positive psychology: On making life worth living for. Terapia Psicologica, 31(1), 5-9. https://doi.org/10.4067/S0718-48082013000100004.

Van Petegem, S., Beyers, W., Brenning, K., \& Vansteenkiste, M. (2013). Exploring the association between insecure attachment styles and adolescent autonomy in family decision making: A differentiated approach. Journal of Youth and Adolescence, 42 (12), 1837-1846.

Wetterneck, C. T., Burgess, A. J., Short, M. B., Smith, A. H., \& Cervantes, M. E. (2012). The role of sexual compulsivity, impulsivity, and experiential avoidance in internet pornography use. 
Psychological Record, 62(1), 3-18. https://doi.org/10.1007/BF033

Wu, C., \& Yang, C. (2012). Attachment and exploration in adulthood:

The mediating effect of social support. International Journal of Psychology, 47(5), 346-354.
Publisher's Note Springer Nature remains neutral with regard to jurisdictional claims in published maps and institutional affiliations. 